\title{
User Experience of Training Pediatric Students on Interactive Simulator During COVID- 9 Pandemic
}

\author{
Guzelle Ernstovna Ulumbekova \\ Rita Rafgatovna Kildiyarova ${ }^{2}$ \\ 'Higher School of Healthcare \\ Organization and Management - \\ Complex Medical Consulting (VSHOUZ), \\ Moscow, Russia; ${ }^{2}$ I.M. Sechenov First \\ Moscow State Medical University, \\ Moscow, Russia
}

Background: COVID-19 pandemic is a reason to revise traditional approaches to medical education. The disadvantage of online education is inability to train practical skills.

Purpose: To evaluate the effectiveness of training students on an interactive pediatric simulator during distance learning.

Patients and Methods: An online survey was conducted during quarantine COVID-19 to clear out the attitude to distance learning of third-year students of the Sechenov First Moscow State Medical University $(n=150)$. During training the level of students' motivation to learn decreased, and what is most important their practical skills deteriorated. Eightyfour out of 150 students had the effectiveness of their training on the multimedia simulator "Filatov. Pediatrics" analyzed.

Results: The simulator reproduces clinical tasks using three-dimensional models of children of different ages and genders and has access to personal computers of students. The cases include imitation of a dialogue with a virtual patient, methods of physical examination, the appointment of laboratory and instrumental methods of research, treatment. The use of a pediatric simulator showed greater efficiency in mastering practical skills compared to a group of students who did not use the simulator in class. Summing up the results of the intermediate objective structured clinical exam (OSCE) on physical examination on dummies of the Simulation and Accreditation Center showed better results in the main group $(n=48)$ compared to the control $(n=36)$. The students who additionally studied on the simulator completed the tasks on the checklist on a cardiology dummy by $98.3 \pm 1.5 \%$. In the control group, the percentage of completed tasks was $94.3 \pm 1.3(\mathrm{p}=0.05)$. The OSCE for examining the respiratory system on an auscultative dummy revealed $97.3 \pm 1.5$ and 93.1 $\pm 1.4 \%$, respectively $(\mathrm{p}=0.05)$.

Conclusion: The interactive pediatric simulator is a tool for mastering practical skills of medical students during the COVID-19 pandemic, with the use of which the OSCE results are significantly higher.

Keywords: students, pediatrics, simulator, efficiency, distance learning

\section{Introduction}

The current situation of the pandemic of the novel coronavirus infection (COVID19) has forced to cast a new look at the organization of distance learning ${ }^{1}$ for medical students. Responding to future pandemics after the current COVID-19 era requires the development of telemedicine applications ${ }^{2}$ using artificial intelligence and robotics. Processes of implementing various online methods ${ }^{3-5}$ of learning have significantly speed up in Russia and in other countries. It was the quarantine that led to a revision of traditional approaches to higher education ${ }^{3,4}$ and opportunities for medical students to gain practical skills. We would like to point out that medicine 
has a special need for new forms of presenting information, $^{6-8}$ including simulation, for assessing its effectiveness and the ways of improving this system in the context of introducing effective educational technologies. I. M. Sechenov First Moscow State Medical University is a leader in digital transformation of new medical education expanding opportunities for teachers, doctors and students. An interactive pediatric program developed in Russia (the Higher School of Healthcare Organization and Management - Complex Medical Consulting (VSHOUZ): https://www.vshouz.ru/), under conditions close to reality, allows you to train and examine future doctors. It helps increase students' satisfaction with the educational process, their involvement, and, consequently, improve the quality of education. Individual studies aimed at obtaining and mastering practical skills for the examination of the patient are also provided in frames of distance learning.

The Objective Structured Clinical Exam (OSCE), ${ }^{9}$ recommended as one of the most reliable methods for diagnosing the success of learning the curriculum, ${ }^{10}$ allows to determine the level of formation of practical actions of students, not only knowledge, as in traditional assessment methods. In Russia, since 2016, the OSCE methodology has been used as the second stage of primary accreditation of specialists, ${ }^{11}$ as well as in almost all situations when it is necessary to assess the level of clinical competence. In the First Moscow State Medical University named after Sechenov the OSCE is used for intermediate certification of all students starting from the second year.

The goal is to evaluate the effectiveness of students' learning using an interactive pediatric simulator during distance education.

\section{Materials and Methods}

\section{Interactive Simulator of a Virtual Patient}

The teaching staff of seven medical universities in Russia and the staff of the Higher School of Healthcare Organization and Management (VSHOUZ, Moscow, Russia) including doctors in management positions and ITspecialists developed the program "Interactive Simulator of a Virtual Patient "Filatov. Pediatrics". The simulator is named to honor the founder of Russian clinical pediatrics Nil Fedorovich Filatov (1847-1902). It reproduces 99 pediatric cases (clinical situational tasks). The simulator has access to a PC and it allows a medical student both to have classes with a professor and to carry out individual work on mastering practical skills. The examination of the patient is held in a virtual office: 3D screen models of children of different ages and genders reproduce the movements of a patient during the examination. The student can close in, turn the virtual child to any position when examining certain parts of his or her body, open his or her mouth, evaluate the mucous membranes, tongue, etc. Modern computer technologies make it possible to simulate palpation: when you hover a computer mouse over the patient's body, a textual description and a visual image of the pathology and palpation technique pop up. The accuracy of the interpretation of lung and heart auscultation ${ }^{12}$ is particularly important in the practice of doctors and medical students. In this regard, when examining the respiratory and cardiovascular systems in a particular virtual patient, the student can perform auscultation: listen to breathing in lungs and heart tones in normal cases and hear wheezing and noises in case of pathology. Symptoms and syndromes that are difficult to simulate on models, as well as additional visual studies, are offered in numerous illustrative materials presented in the course of follow-up patient management. The program provides a summary report that determines the percentage of completed or unfulfilled tasks. So with the help of an interactive simulator you can both train and evaluate the effectiveness of training for students.

\section{Study Design}

Evaluation of the effectiveness of distance learning system in the context of COVID-19 pandemic was conducted by a survey held among third-year students $(n=150)$ of the Sechenov First Moscow State Medical University. The inclusion criteria were as follows: students of the pediatric faculty of the Medical University, age 18-21, period of online study. Exclusion criteria: students of other faculties, under the age of 18 or over the age of 21 , traditional education. An online questionnaire was formed using Google forms: it included questions concerning respondents' personal data and students' attitude to distance learning, some of the answers are cited in this study. Among the study participants, $16.7 \%$ were male, $83.3 \%$ were female, the average age was $19.0+1.4$ years; the duration of distance learning was 5 months (February-June, 2020).

The effectiveness of an interactive pediatric simulator based on the results of the OSCE was analyzed on 84 out of 150 students who were on distance learning. The basic group $(n=44)$ was formed for this purpose, students were 
able to train individually on the interactive simulator "Filatov. Pediatrics" (Figure 1). There was no training on a pediatric simulator in the control group $(n=40)$.

All the figures obtained for analyzing the effectiveness of distance learning and evaluating the effectiveness of teaching on an interactive pediatric simulator are original. We have received approval for the application for approval of this study from the Ethics Committee of LLC "Higher School of Health Organization and Management Comprehensive Medical Consulting". The number of ethical approval for the study is $\mathrm{N} 7 / \mathrm{KD}$. The photos presented in the work were made by the author during the student exam. The teachers in Figures 2 and 3 have provided informed consent for the images to be published.
Before passing the OSCE, all students were given one four-hour lesson on the Harvey cardiology simulation manikin and the auscultative manikin SAM II. Both manikins are ideal to practice heart and lung auscultation. A list of control questions or checklists for physical examination of the cardiovascular and respiratory systems related to binary ("yes/ no") has been developed for conducting the OSCE. The assessment was made depending on whether the task was completed or not without specifying the quality of its performance, so the checklists were intended to determine the minimum level of competence. The results in both groups were summed up in percentage points. Interpretation of the exam checklists objectivity held afterwards provided for a minimum of $80 \%$ of the completed tasks.

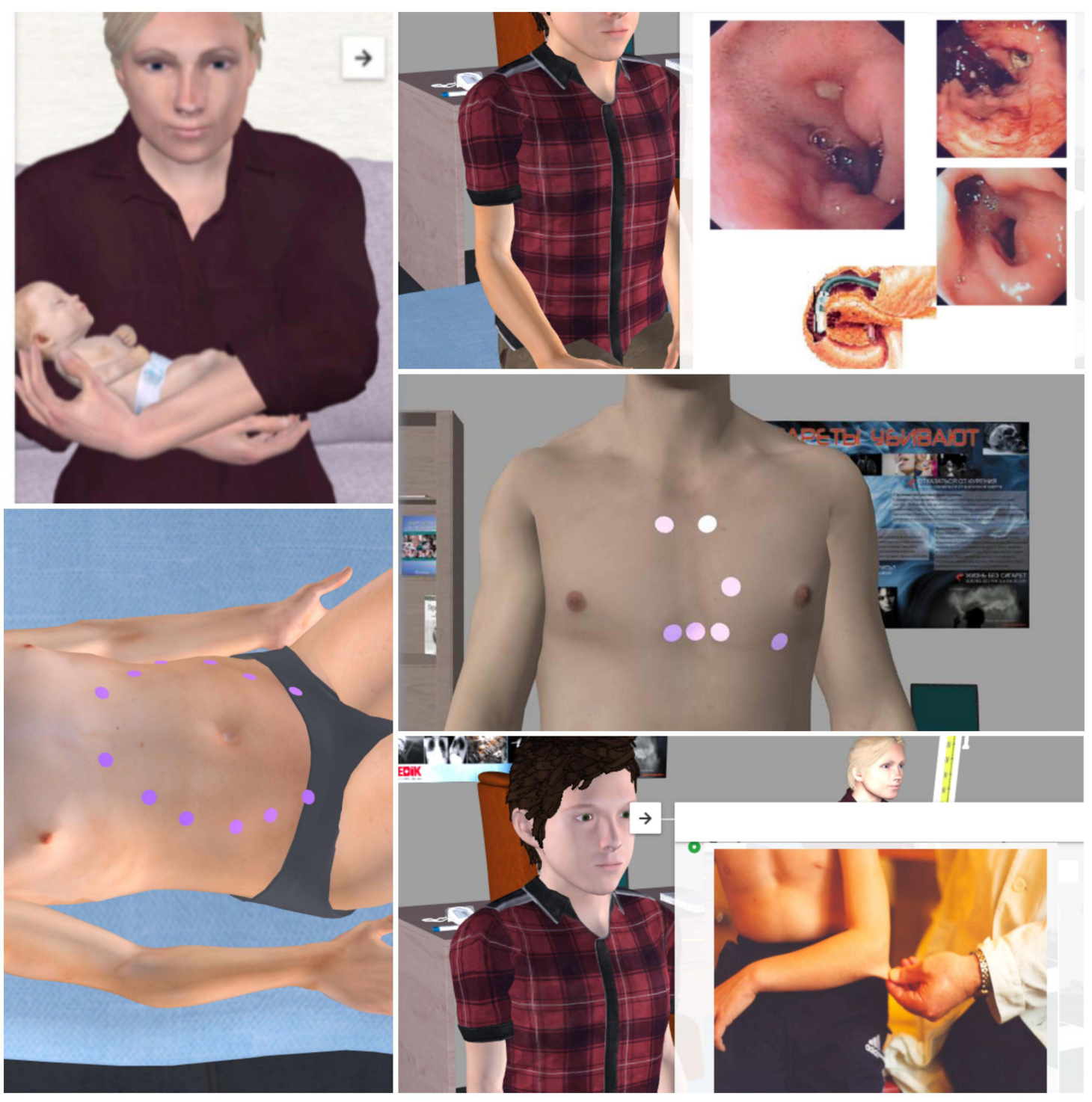

Figure I The interactive simulator "Filatov. Pediatrics": opportunities for examining children of different age groups. 


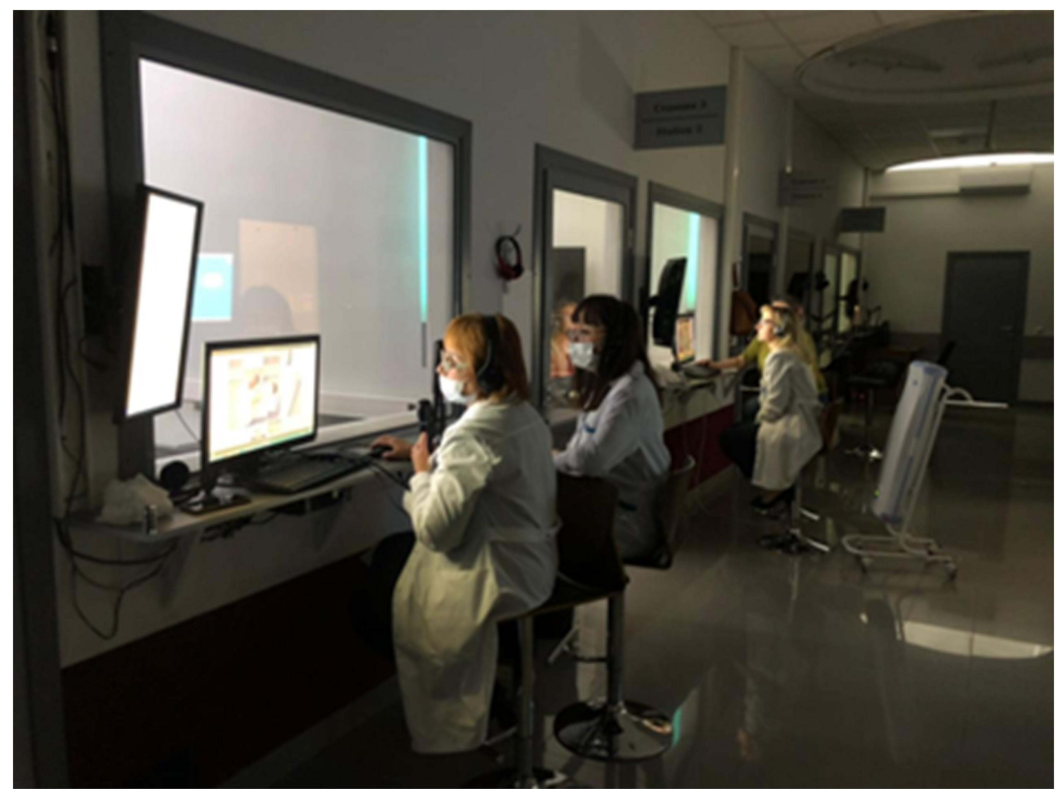

Figure 2 Teachers at the OSCE exam in the Simulation and Accreditation Center of the I. M. Sechenov First Moscow State Medical University.

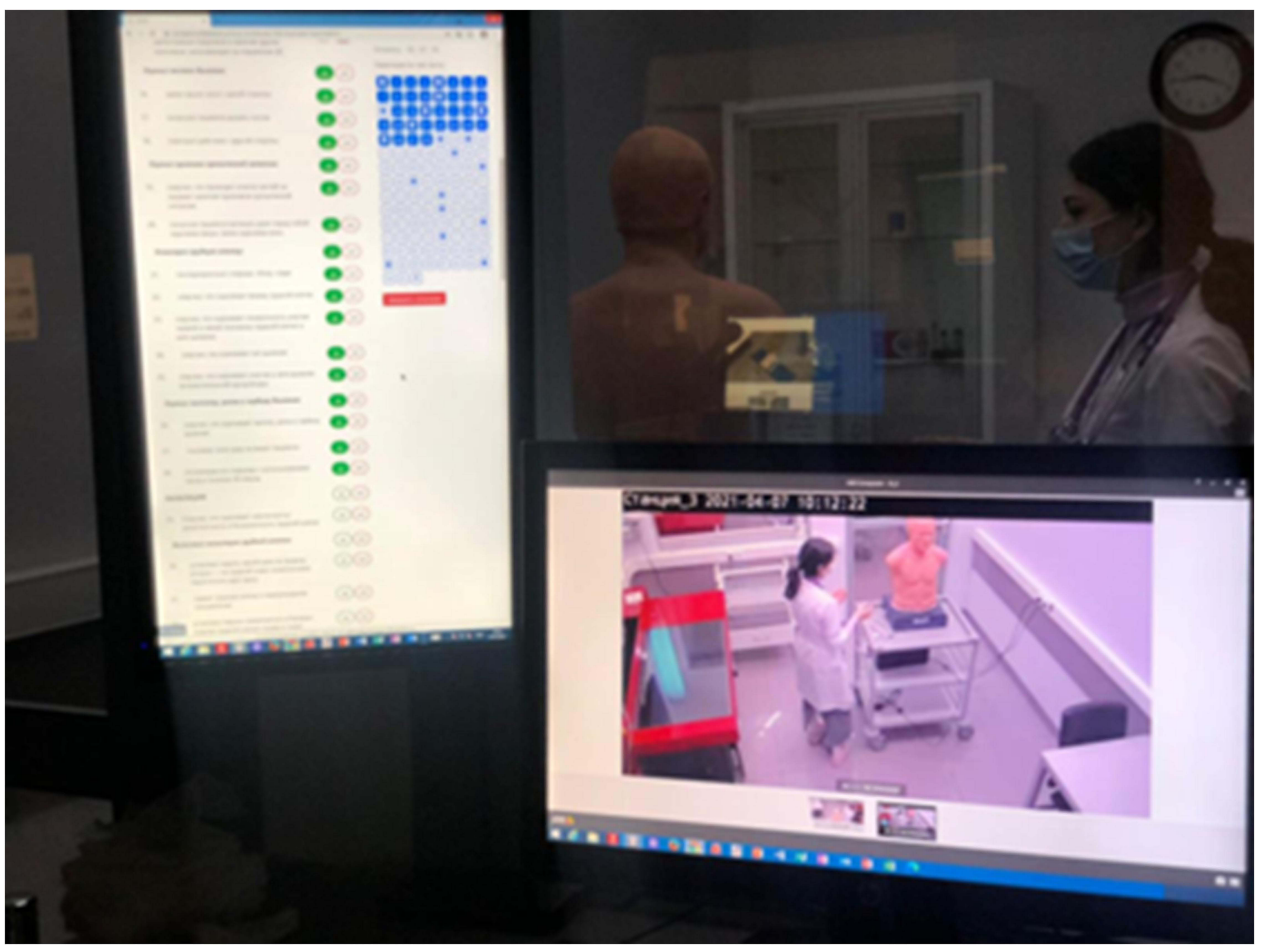

Figure 3 A student submits a checklist for a physical examination of the respiratory system OSCE.

\section{Statistical Analysis}

Statistical processing of the obtained results (student questionnaires, results of the OSCE checklists) was performed using the Microsoft Excel program. Quantitative indicators are presented as the median of the 25 th, 75 th percentiles. The differences between the compared values were considered significant at $\mathrm{p}=0.05$.

\section{Results}

There are quite a lot of factors that affect distance learning of the trainees. Besides, medical students can 
depersonalize and hedge ${ }^{13}$ by giving negative feedback to clinical teachers. According to the study, satisfaction with various aspects of the learning process at the University significantly decreased during the period of implementing educational programs with distance learning technologies. First of all, it refers to a decrease in the level of motivation for further training, the deterioration of practical skills in every second or third student. Apart from university textbooks and electronic resources, students use other Internet information including video materials more frequently. Both teachers and students have difficulties in assessing the acquired knowledge and especially practical skills (Table 1). The results obtained are new and original.

As we see, the majority of students mentioned difficulties in obtaining practical skills, new information and decrease in their motivation for further education.

Working individually on a pediatric simulator, the students from the basic group were able to master the method of physical examination and prepare for the OSCE much better. Hard work of the authors' team in VSHOUZ, who created an interactive simulator of a virtual pediatric patient, turned out to be self-sufficient, spectacular, and, what is most important, effective for obtaining practical skills.

Table I Questionnaire Survey of Pediatric Students Using Google Forms

\begin{tabular}{|c|c|c|}
\hline Survey Questions & $\begin{array}{l}\text { Variants of } \\
\text { Answers }\end{array}$ & $\begin{array}{l}\text { Gained } \\
\text { Results,\% }\end{array}$ \\
\hline $\begin{array}{l}\text { What materials are convenient/ } \\
\text { preferred/used for distance } \\
\text { learning? }\end{array}$ & $\begin{array}{l}\text { Internet information } \\
\text { resources } \\
\text { Video materials } \\
\text { Printed tutorials }\end{array}$ & $\begin{array}{l}68.6 \pm 3.5 \\
96.6 \pm 2.5 \\
37.3 \pm 4.5\end{array}$ \\
\hline $\begin{array}{l}\text { Do you evaluate your } \\
\text { knowledge? }\end{array}$ & $\begin{array}{l}\text { No, I do not } \\
\text { I conduct testing } \\
\text { My professor does it }\end{array}$ & $\begin{array}{l}20.0 \pm 5.2 \\
95.6 \pm 7.2 \\
82.6 \pm 8.3\end{array}$ \\
\hline $\begin{array}{l}\text { Did your training at the } \\
\text { University Simulation and } \\
\text { Accreditation Center help you? }\end{array}$ & $\begin{array}{l}\text { No } \\
\text { Yes }\end{array}$ & $\begin{array}{l}20.0 \pm 5.2 \\
80.0 \pm 6.7\end{array}$ \\
\hline $\begin{array}{l}\text { Evaluate your practical skills in } \\
\text { distance learning using } \\
\text { checklists compared to } \\
\text { traditional ones }\end{array}$ & $\begin{array}{l}\text { Worse } \\
\text { Better } \\
\text { The same }\end{array}$ & $\begin{array}{l}35.3 \pm 4.4 \\
15.3 \pm 3.5 \\
49.4 \pm 5.2\end{array}$ \\
\hline $\begin{array}{l}\text { Has your motivation for further } \\
\text { studies changed when distance } \\
\text { learning was introduced? }\end{array}$ & $\begin{array}{l}\text { Decreased } \\
\text { Not changed } \\
\text { Increased }\end{array}$ & $\begin{array}{l}43.3 \pm 5.4 \\
44.0 \pm 5.5 \\
12.7 \pm 3.8\end{array}$ \\
\hline
\end{tabular}

At the OSCE, students visited two stations in the University Simulation and Accreditation Center and received the same set of tasks on the checklists. Each examinee was evaluated by trained examiners who observed the performance of tasks in different sections (Figure 2). Computer-controlled simulators with objective evaluation for a specific time, used at the stations, included fulfilling checklists developed separately for each system (Figure 3).

The students of the main group $(\mathrm{n}=48)$ had a significantly higher efficiency of mastering practical skills compared to the control group $(\mathrm{n}=36)$. This fact is confirmed by the results of the intermediate OSCE on the physical examination of dummies at the Simulation and Accreditation Center. Students who additionally studied on the online pediatric simulator completed the checklist tasks on a cardiology dummy by $98.3 \pm 1.5 \%$. In the control group, the percentage of completed tasks was $94.3 \pm 1.3(\mathrm{p}=0.05)$. There were also better results in the main group compared to the control one on the auscultative dummy. The exam on the checklists of the respiratory system examination revealed $97.3 \pm 1.5$ and $93.1 \pm 1.4 \%$ of the results in students, respectively $(\mathrm{p}=0.05)$.

\section{Discussion}

For a long time, clinical pediatrics ${ }^{14}$ has been based on a traditional physician training program. The program based on the observation of real patients in real conditions became impossible during COVID-19 pandemic. It was proved in pre-COVID time that digital education for medical professions is as effective as traditional training, ${ }^{14}$ or more effective ${ }^{15}$ than no training. Since early 2000s gamification $^{15}$ has become a method of mass learning - the way when the rules of the game are applied to achieve real goals. The need for simulation dummies, such as a student auscultation dummy, ${ }^{17,18}$ for the educational process is justified. Another cardiopulmonary patient simulator ${ }^{10,19}$ is considered to be one of the pioneering products in medical simulation that provides a standardized testing method for real-time procedures and trainee skills. The advantages of simulation training are the possibility of making mistakes without harming the dummy, ${ }^{14,16}$ the possibility of repeated repetition and the development of practical skills which is especially true for cardiopulmonary auscultation with high sound quality. 
If it is not possible to visit simulation centers in order to prevent the spread of COVID-19 cases, you may resort to other online simulators. The developed interactive pediatric program with access to a PC allows you to train and test future doctors under conditions close to reality using three-dimensional characters of different genders and ages. There is an opportunity to increase students' satisfaction with the educational process, their involvement and, consequently, to improve the quality of education. In the framework of distance learning individual work is provided with a focus on obtaining practical skills for examining the patient concerning all stages of physical examination - anamnesis, examination, palpation, percussion, and auscultation.

The Objective Structured Clinical Examination $(\mathrm{OSCE})^{8}$ is a method used to assess clinical competence. Harden et al, ${ }^{9}$ who first applied this estimation method in 1975, gives it the following definition:

An approach to the assessment of clinical or professional competence in which the components of competence are evaluated in a planned and structured manner with a special attention to the objectivity of the assessment.

Unlike traditional oral exams, the formation of clear instructions in checklists ${ }^{9}$ at the stations allows to make the educational process controlled and predictable. Another practical advantage of the OSCE is the ability to determine the criteria for passing the exam ${ }^{10}$ in advance and provide feedback to the teaching staff and students after the exam.

\section{Conclusion}

To improve the effectiveness of distance medical learning, we recommend to use an interactive pediatric simulator with access to personal computers of professors and students. Clinical case studies will help develop the creativity and skills of future pediatricians during a pandemic, especially when they are studying or preparing for exams on their own. The pediatric simulator can be considered as a tool for mastering practical skills. Replacing traditional training in clinical practice with alternative approaches helps maintain contact with the virtual patient being examined without any risk of COVID-19 infection.

Working with pediatric cases on various diseases in children of different age groups helped third-year students of the University master practical skills and significantly better pass the intermediate OSCE on the checklists of the patient's physical examination. Further differential diagnosis drawing up a plan of laboratory and instrumental studies with interpreting results of the virtual patient will teach pediatricians to make fewer mistakes, to find the correct clinical diagnosis, prescribe rational treatment and develop their professional competencies.

\section{Author Contributions}

All authors made a significant contribution to the work reported, whether that is in the conception, study design, execution, acquisition of data, analysis and interpretation, or in all these areas; took part in drafting, revising or critically reviewing the article; gave final approval of the version to be published; have agreed on the journal to which the article has been submitted; and agree to be accountable for all aspects of the work.

\section{Disclosure}

The authors report no conflicts of interest in this work.

\section{References}

1. Sharma D, Bhaskar S. Addressing the Covid-19 burden on medical education and training: the role of telemedicine and tele-education during and beyond the pandemic. Front Public Health. 2020;8:838. doi:10.3389/fpubh.2020.589669

2. Bhaskar S, Bradley S, Sakhamuri S, et al. Designing futuristic telemedicine using artificial intelligence and robotics in the COVID-19 era. Front Public Health. 2020;8:556789. doi:10.3389/fpubh.2020. 556789

3. Almarzooq ZI, Lopes M, Kochar A. Virtual learning during the COVID-19 pandemic: a disruptive technology in graduate medical education. J Am Coll Cardiol. 2020;75(20):2635-2638. doi:10.1016/ j.jacc.2020.04.015

4. Dost S, Hossain A, Shehab M, Abdelwahed A, Al-Nusair L. Perceptions of medical students towards online teaching during the COVID-19 pandemic: a national cross-sectional survey of $2721 \mathrm{UK}$ Medical Students. BMJ Open. 2020;10(11):e042378. doi:10.1136/ bmjopen-2020-042378

5. Levanov VM, Perevezentsev EA, Gavrilova AN. Distance learning in a medical university during the COVID-19 pandemic: the first experience through the eyes of students. Telemed J E Health. 2021. Available from: https://evercare.ru/news/distancionnoe-obrazovanie -v-medicinskom-vuze-v-period-pandemii-covid-19-pervyy-opytglazami. Accessed March 18, 2021.

6. Issenberg SB, Gordon MS, Gordon DL, Saford RE. Simulation and new learning technologies. Med Teach. 2001;16:16-23. doi:10.1080/ 01421590020007324

7. Issenberg SB, Mc Gaghie WC, Petruss ER. Features and uses of high-fidelity medical simulations that lead to effective learning: BEME systemic review. Med Teach. 2005;1(27):10-28.

8. Khan K, Ramachandran S. Conceptual framework for performance assessment: competency, competence and performance in the context of assessments in healthcare - deciphering the terminology. Med Teach. 2012;34:920-928. doi:10.3109/0142159X.2012.722707

9. Harden RM, Stevenson M, Downie WW, Wilson GM. Assessment of clinical competence using objective structured examination. $\mathrm{Br}$ Med J. 1975;1(5955):447-451. doi:10.1136/bmj.1.5955.447

10. Tavakol M, Dennick R. Post-examination interpretation of objective test data: monitoring and improving the quality of high-stakes examinations: AMEE Guide No. 66. Med Teach. 2012;34(3):e161-e175. 
11. Alekseyeva AU, Balkizov ZZ, Perelman V, Semenova TV, Sizova ZM. Objective structured clinical examination as a tool for accreditation of medical specialists. Med Educ Prof Dev. 2018;1:15-18.

12. Hafke-Dys H, Breborowicz A, Kleka P, Kocinski J, Biniakowski A. The accuracy of lung auscultation in the practice of physicians and medical students. PLoS One. 2019;14(8):e0220606. doi:10.1371/journal.pone.0220606

13. Olvet DM, Willey JM, Bird JB, Rabin JM. Third-year medical students impersonalize and hedge when providing negative upward feedback to clinical faculty. Med Teach. 2021;43(6):700-708. doi:10.1080/0142159X.2021.1892619

14. McGaghie WC, Issenberg SB, Cohen ER, Barsuk JH, Wayne DB. Does simulation-based medical education with deliberate practice yield better results than traditional clinical education? A meta-analytic comparative review of the evidence. Acad Med. 2011;86(6):706-711. doi:10.1097/ACM.0b013e3182 $17 \mathrm{e} 119$
15. Brusamento S, Kyaw BM, Whiting P, Li L, Tudor Car L. Digital health professions education in the field of pediatrics: systematic review and meta-analysis by the digital health education collaboration. $\mathrm{J} \mathrm{Med}$ Internet Res. 2019;21(9):e14231. doi:10.2196/14231

16. Kaminsky J, Bianchi R, Eisner S, et al. Respiratory auscultation labusing a cardiopulmonary auscultation simulation Manikin. MedEdPORTAL. 2021;17:11107. doi:10.15766/mep 2374-8265.11107

17. Vacher E, Bruessel P. Response to: coronavirus disease 2019 (COVID-19) learning online: a flipped classroom based on micro-learning combined with case-based learning in undergraduate medical students. Adv Med Educ Pract. 2021;12:1127-1128. doi:10.2147/AMEP.S339573

18. Gordon MS, Ewy GA, Deleon AC, et al. "Harvey," the cardiology patient simulator: pilot studies on teaching effectiveness. $\mathrm{Am}$ J Cardiol. 1980;45(4):791-796. doi:10.1016/0002-9149(80)90123-x

19. Quinn A, Kaminsky J, Adler A, Eisner S, Ovitsh R. Cardiac auscultation lab using a heart sounds auscultation simulation manikin. MedEdPORTAL. 2019;15:10839. doi:10.15766/mep_2374-8265.10839

\section{Publish your work in this journal}

Advances in Medical Education and Practice is an international, peerreviewed, open access journal that aims to present and publish research on Medical Education covering medical, dental, nursing and allied health care professional education. The journal covers undergraduate education, postgraduate training and continuing medical education including emerging trends and innovative models linking education, research, and health care services. The manuscript management system is completely online and includes a very quick and fair peer-review system. Visit http://www.dovepress.com/testimonials.php to read real quotes from published authors. 